\title{
Body mass index and Blount's disease: a single academic hospital experience
}

\author{
Kgoedi MN1 ${ }^{1}$, Rischbieter $\mathrm{P}^{2}$, Goller $\mathrm{R}^{3}$ \\ 1 MBChB(UFS); Registrar Orthopaedic Surgery, University of Pretoria, Pretoria, South Africa \\ $2 \mathrm{MBChB}(\mathrm{UP})$; Registrar Radiology, University of Pretoria, Pretoria, South Africa \\ 3 MBChB, FCS Ortho(SA), MMed(Ortho); Specialist Orthopaedic Surgeon, Department of Orthopaedic Surgery, University of Pretoria, Pretoria, \\ South Africa
}

Corresponding author: Dr MN Kgoedi, Orthopaedic Department Level 7, Steve Biko Academic Hospital, cnr Steve Biko Road and Savage Street, Gezina, Pretoria, 0001; email: nelsonkgoedi@gmail.com; tel: +27 123542851

\begin{abstract}
Background: Blount's disease is a developmental disorder of the proximal tibia with progressive varus, flexion and internal rotation deformity. It is often seen in overweight children and strongly associated with obesity. As the prevalence of childhood obesity is increasing worldwide, the incidence of Blount's disease has been noted to be on the increase as well. In the South African population, most children are malnourished with high levels of undernutrition compared to other middle-income countries. We hypothesised that in our institution, patients with Blount's disease have a body mass index (BMI) lower than reported in studies from mainly developed countries. The aim of the study was to investigate the relationship between BMI and Blount's disease in a South African academic institution.
\end{abstract}

Methods: All clinical and radiological records of patients with Blount's disease at a tertiary hospital in South Africa over a six-year period were retrospectively reviewed. Five patients did not meet inclusion criteria and were excluded from the study. Data collected included patients' demographics, weight, height and radiological investigations. A control group of randomly selected paediatric orthopaedic patients was studied.

Results: A total of 39 Blount's patients (19 females, 20 male) were studied. All the Blount's patients were of black ethnicity. There were nine patients with early-onset and 30 patients with late-onset Blount's disease. The mean BMls for Blount's disease and control groups were $26 \mathrm{~kg} / \mathrm{m}^{2}$ and $20 \mathrm{~kg} / \mathrm{m}^{2}$ respectively ( $\left.<<0.001\right)$. There was no statistical difference in sex, laterality, BMI and BMI-percentiles (BMI\%) between early-onset and late-onset Blount's disease. There was no relationship between BMl and severity of Blount's disease deformities.

Conclusion: High BMI is associated with Blount's disease in the cohort studied. There was no relationship between increasing BMI and severity of Blount's deformities. No relationship was found between sex, onset or laterality and Blount's disease in our study.

Level of evidence: Level 4

Key words: Blount's disease, body mass index, childhood obesity, metaphyseal-diaphyseal angle, tibio-femoral shaft angle

Citation: Kgoedi MN, Rischbieter P, Goller R. Body mass index and Blount's disease: a single academic hospital experience. SA Orthop J 2019;18(1):15-20. http://dx.doi.org/10.17159/2309-8309/2019/v18n1a1

Editor: Prof Jacques du Toit, Stellenbosch University, South Africa

Copyright: ( 2019 Kgoedi MN. This is an open-access article distributed under the terms of the Creative Commons Attribution Licence, which permits unrestricted use, distribution and reproduction in any medium, provided the original author and source are credited.

Funding: No funding was received with respect to research and preparation of this article.

Conflict of interest: The authors declare no potential conflict of interest with respect to research, authorship and publication of this study. 


\section{Introduction}

Blount's disease is a developmental condition characterised by disordered endochondral ossification of the medial part of the proximal tibial growth plate resulting in multi-planar deformities of the lower limb.1,2 Secondary to the asymmetrical growth with relative inhibition of the posteromedial portion of the proximal tibial growth plate, a three-dimensional deformity of the tibia develops with varus, procurvatum (apex anterior), and internal rotation along with possible limb shortening in unilateral cases..$^{1,2}$ This entity can lead to a progressive deformity with gait abnormalities, limblength discrepancy, and premature arthritis of the knee., Blount's disease is classified into early-onset (infantile) and late-onset based on whether the limb deformity develops before or after the age of four years..$^{2-4}$ It is classified radiologically by Langenskiold into six progressive stages per severity of the deformity to help in prognosticating patients' outcome. ${ }^{4-7}$ The incidence of Blount's disease in South Africa was estimated to be $0.03 \%$ three decades ago. $^{8}$

The aetiology of Blount's disease remains unknown, though multifactorial origin is proposed with genetic and mechanical components contributing to its development. ${ }^{3}$ There is a predisposition of black children to develop Blount's disease compared to other racial groups. ${ }^{3}$ Blount's disease has been linked to increasing weight and vitamin $D$ deficiency. ${ }^{1,2,9,10} A$ number of studies show a strong correlation between Blount's disease and obesity. 3,10-14 Lisenda et al. found no independent association between vitamin $D$ deficiency and Blount's disease in their study in South African children. ${ }^{15}$ Obesity has been shown to greatly increase the medial compartment pressure and contribute to the development of Blount's disease by the Heuter-Volkmann principle. ${ }^{16}$

Limited research is inconclusive on the relationship between increasing body mass index (BMI) and the severity of Blount's disease deformity. ${ }^{11,13} \mathrm{~A}$ strong correlation has been found only between morbid obesity and radiological deformities of earlyonset Blount's disease. ${ }^{13}$ As the prevalence of childhood obesity is increasing worldwide, Blount's disease has been noted to be on the increase as well. ${ }^{1,16}$ In a retrospective study of 44 Blount's disease patients by Sabharwal et al., the average BMI was 35.6, with the average BMI of 29.2 for early-onset and 39.7 for late-onset Blount's disease. ${ }^{13}$

Childhood obesity has doubled in the past three decades. The percentage of children aged 6-11 years who were obese increased from $7 \%$ in 1980 to nearly $18 \%$ in 2012 in the United States. ${ }^{17}$ Similarly, the percentage of adolescents aged 12-19 years who were obese increased from $5 \%$ to nearly $21 \%$ over the same period. ${ }^{17}$ In 2012, more than one-third of children and adolescents were either overweight or obese. ${ }^{17}$ It has been estimated that over 22 million children under the age of 5 years are obese worldwide. ${ }^{18}$ The prevalence of being overweight in Africa and Asia averages below $10 \%$ while in America and Europe it averages above $20 \% .^{18}$

In the South African population, many children are malnourished compared to other middle-income countries. ${ }^{19-23}$ Micronutrient malnutrition is regarded as a public health problem of considerable significance in South Africa. . $^{19,22,23}$ South African children aged 1 to 9 years have an intake of less than $67 \%$ of the recommended dietary allowances (RDAs) for energy, calcium, vitamin $\mathrm{D}$ and other micronutrients. ${ }^{19,22,23}$ In a national study conducted in $2004,10 \%$ of children were classified as overweight and $4 \%$ as obese in South Africa. ${ }^{22}$ The Health of the Nation Study, estimated an increase in overweight from $1.2 \%$ to $13 \%$ and in obesity from $0.2 \%$ to $3.3 \%$ over the period from 1994 to 2004, and more recent studies showed a mean prevalence of just over $15 \%$ for overweight and obesity combined. ${ }^{24}$
The purpose of this study was to investigate the BMI profile and demographics of patients with Blount's disease in the South African context and determine the relationship between body weight and Blount's disease and the severity of angular deformities. We hypothesised that in our institution, patients with Blount's disease have a higher BMI than the general paediatric population, but still lower than reported studies from mainly developed countries. The second hypothesis was that increasing BMI is associated with worsening angular deformities.

\section{Material and methods}

A retrospective review of clinical and radiological records was conducted of all patients with Blount's disease that attended the Paediatric Orthopaedic Unit from 1 January 2011 to 31 December 2016. Patients' details were obtained from the surgical database and outpatient records. Patients' folders were retrieved from the records department. Radiological images of all patients were available from the hospital's picture archiving and communication system (PACS). All patients diagnosed with Blount's disease were included in the study. Patients were grouped into four ethnicities, i.e. black, white, coloured and Indian. Incomplete clinical records, other congenital abnormalities and patients over 20 years of age were excluded from the study.

A randomised control group of 100 paediatric orthopaedic patients was included in the study to achieve a ratio of at least 2:1 for statistical analysis. This included patients that were treated for injuries with clinical records of weight and height. Patients with other congenital abnormalities/deformities and patients over 20 years of age were excluded from the control group. A simple randomisation method was utilised to obtain a representative sample of the control group from 1 January 2016 to 31 December 2016. The control group consisted of patients seen in 2016, grouped by sex. Each was allocated a number and a random number generator was utilised to obtain a sample of 50 patients for each sex. BMls were calculated from the patients' weight and height records. The BMls were interpreted as follows: $<18.5 \mathrm{~kg} / \mathrm{m}^{2}$ as underweight, $18.6-24.9 \mathrm{~kg} / \mathrm{m}^{2}$ as normal, $25-30 \mathrm{~kg} / \mathrm{m}^{2}$ as overweight and $>30 \mathrm{~kg} / \mathrm{m}^{2}$ as obese. ${ }^{9} \mathrm{BMI}$ percentiles (BMI\%) were plotted using the 2000 Centre for Disease Control and Prevention age- and sexspecific charts for every patient.

Patients' radiological images were studied for classification of Blount's disease using the Langenskiold classification system. This is a staging system of Blount's disease according to the degree of metaphyseal-epiphyseal changes seen on radiographs used to prognosticate outcomes. ${ }^{2,4,5}$ Stage I is defined as presence of medial epiphyseal beaking; stage II is described as a saucershaped defect of medial metaphysis; stage III is when the saucer defect deepens into a step; stage IV is when the epiphysis is bent down over the medial beak; stage $\mathrm{V}$ when there is the presence of a double epiphysis; and stage VI when there is development of a medial physeal bony bar. ${ }^{2,4,5}$ These were further categorised as low grade (Langenskiold stages I-IV) and high grade (Langenskiold stages $\mathrm{V}-\mathrm{VI}$ ) Blount's disease. ${ }^{7,25}$

Tibio-femoral angles (TFA) were calculated on the PACS images and recorded for each patient. X-rays were full weightbearing with the patella facing forward. All data collected was recorded onto Microsoft Excel spreadsheet for analysis. Ethics approval was obtained prior to commencement of the study.

\section{Statistical methods}

The descriptive statistics were used with the assistance of a statistician. Standard deviation and ranges, with 95\% confidence intervals for body mass indices in children with Blount's disease and 
Table I: Summary of Blount's patients' demographic data

\begin{tabular}{|c|c|c|c|c|}
\hline & & Early & Late & Total \\
\hline Number of patients & & 9 & 30 & 39 \\
\hline \multicolumn{5}{|l|}{ Sex } \\
\hline & Male & 4 & 16 & 20 \\
\hline & Female & 5 & 14 & 19 \\
\hline \multicolumn{5}{|l|}{ Laterality } \\
\hline & Unilateral & 4 & 16 & 20 \\
\hline & Bilateral & 5 & 14 & 19 \\
\hline \multicolumn{5}{|c|}{ Langenskiold classification } \\
\hline & Stage I & 2 & 0 & 2 \\
\hline & Stage II & 9 & 7 & 15 \\
\hline & Stage III & 6 & 1 & 7 \\
\hline & Stage IV & 0 & 11 & 11 \\
\hline & Stage V & 1 & 14 & 15 \\
\hline & Stage VI & 0 & 8 & 8 \\
\hline
\end{tabular}

Table II: Mean BMI values of the subgroups of Blount's disease patients

\begin{tabular}{|ll|l|l|}
\hline & & Mean BMI & P-value \\
\hline Onset & $\begin{array}{l}\text { Early } \\
\text { Late }\end{array}$ & 24.2 & 0.459 \\
\hline Sex & 27.7 & \\
\hline & Male & 27.7 & 0.4489 \\
\hline & Female & 25.3 & \\
\hline Laterality & Unilateral & 23.2 & 0.0275 \\
& Bilateral & 29.9 & \\
\hline
\end{tabular}

Table III: Classification of Blount's patients and the control group based on BMI percentile ranges (CDC 2000 percentile chart)

\begin{tabular}{|l|l|l|l|}
\hline \multicolumn{1}{|c|}{ Percentile } & \multicolumn{1}{c|}{ Blount's } & \multicolumn{1}{c|}{ Control } & \multicolumn{1}{c|}{ Total } \\
\hline <5th (underweight) & $13 \%(5)$ & $3 \%$ & $5.76 \%$ \\
\hline 5th to 85th (normal) & $15 \%(6)$ & $46 \%$ & $37.4 \%$ \\
\hline 85th to 95th (overweight) & $13 \%(5)$ & $11 \%$ & $11.51 \%$ \\
\hline >95th (obese) & $59 \%(23)$ & $40 \%$ & $45.32 \%$ \\
\hline \multicolumn{3}{|c|}{ Fisher's exact $=0.002$} & \\
\hline
\end{tabular}

the control group were calculated. The t-test and Wilcoxon ranksum (Mann-Whitney) test were used to determine differences in BMI between early-onset and late-onset Blount's disease children.

Cross-tabulations of categorical variables with Fisher's exact and chi-squared tests were done to assess for associations. The frequency distributions in terms of BMI and BMI\% of early-onset and late-onset Blount's disease were compared using the chisquared test. The two-sample Wilcoxon rank-sum (Mann-Whitney) test was used to determine statistically significant differences in BMl between the Blount's disease group and the control group, controlling for age. Pearson's correlations were used to assess the relationship between BMI and angular deformity (TFA), and a univariate logistic regression model using BMI to predict the Langenskiold classification for severity was assessed. Significance was determined at $p$-value $<0.05$ for all statistical analyses. Statistical analysis was done using STATA 14 (StataCorp, 4905 Lakeway Drive, College Station, Texas, USA).

\section{Results}

Forty-four Blount's disease patients were identified. Five patients were excluded from the study (three had no weight and height records and two had no radiographs on PACS). Records and radiographs of 39 patients were retrospectively analysed. There were 20 male patients and 19 female patients with a mean age of 7.5 years (range: 1-15). A summary of the patient data is given in Table I. There was no difference in sex distribution of both earlyonset (infantile) and late-onset (juvenile and adolescent) Blount's disease patients. The mean age was 3 years (range: $2-4$ ) for earlyonset Blount's disease and 10 years (range: 5-17) for late-onset Blount's disease patients. All Blount's disease patients were of black ethnicity. A total of 100 control patients were studied. The control group had 50 male and 50 female patients with a mean age of 8.4 years (range: $2-17$ ).

The mean BMl for Blount's disease patients was $26.5 \mathrm{~kg} / \mathrm{m}^{2}$ (range: 12-44) with early-onset Blount's patients having a mean of $24.2 \mathrm{~kg} / \mathrm{m}^{2}$ (range: 12-44) and $27.7 \mathrm{~kg} / \mathrm{m}^{2}$ (range: 12-43) for lateonset Blount's patients (Table II). There was no statistical difference between the mean BMI of early-onset and late-onset Blount's disease patients $(p=0.3944)$, although the late-onset group had a slightly higher mean BMI. The mean BMls of male and female patients with Blount's disease were $27.7 \mathrm{~kg} / \mathrm{m}^{2}$ and $25.3 \mathrm{~kg} / \mathrm{m}^{2}$ respectively $(p=0.4489)$.

There was no association between laterality and onset of Blount's disease (early vs late) with Pearson chi-squared $=0.22$ with $p$-value $=0.64$ and Fisher's exact $=0.72$. There was a statistically significant difference between the mean BMI of patients with unilateral disease $23.2 \mathrm{~kg} / \mathrm{m}^{2}$ (range: $12-40$ ) and bilateral disease $29.9 \mathrm{~kg} / \mathrm{m}^{2}$ (range 13-44) with $p$-value $=0.0275$ ). The mean BMI for the control group was $20.2 \mathrm{~kg} / \mathrm{m}^{2}$ (range: 12-36). There was a statistically significant difference between the mean BMI of Blount's disease patients and the control group ( $p$-value $=0.0005$ ) .

Table III presents a comparison of BMI\% between Blount's disease patients and the control group based on the CDC criteria for children (Fisher's exact $=0.002$ ). Five $(56 \%)$ of nine children with early-onset Blount's disease and $18(60 \%)$ of 30 patients with late-onset Blount's disease were classified as obese (Fisher's exact $=0.459)$. Five $(17 \%)$ of the 30 patients with late-onset Blount's disease and none of nine patients with early-onset Blount's disease were classified as overweight.

Using BMI values to interpret categories without controlling for age and sex shows that $31 \%$ of Blount's patients are underweight (Figure 1). This was disproved by using BMI-for-age percentiles, highlighting the importance of using the age- and sex-adjusted percentiles (CDC 2000 charts) to interpret BMI values in children. 


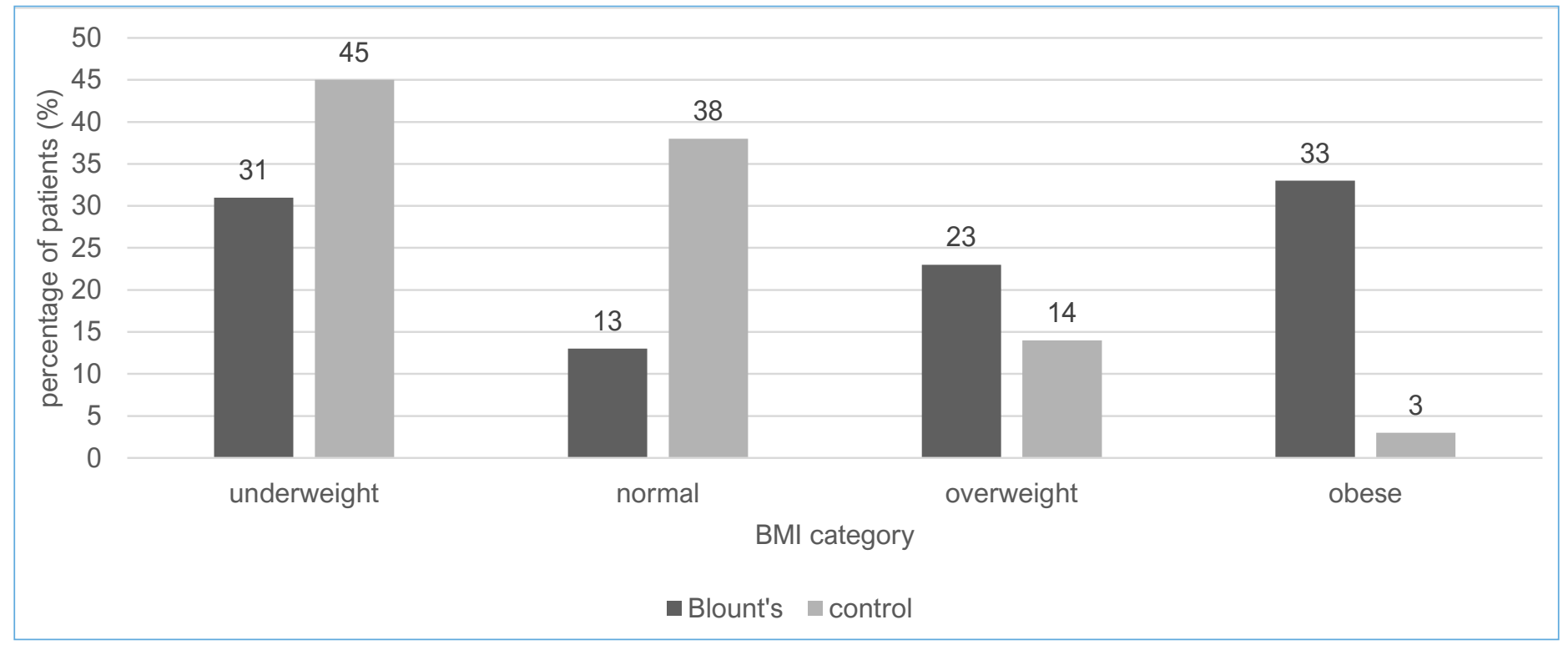

Figure 1. Body mass index categories of Blount's disease patients and the control group

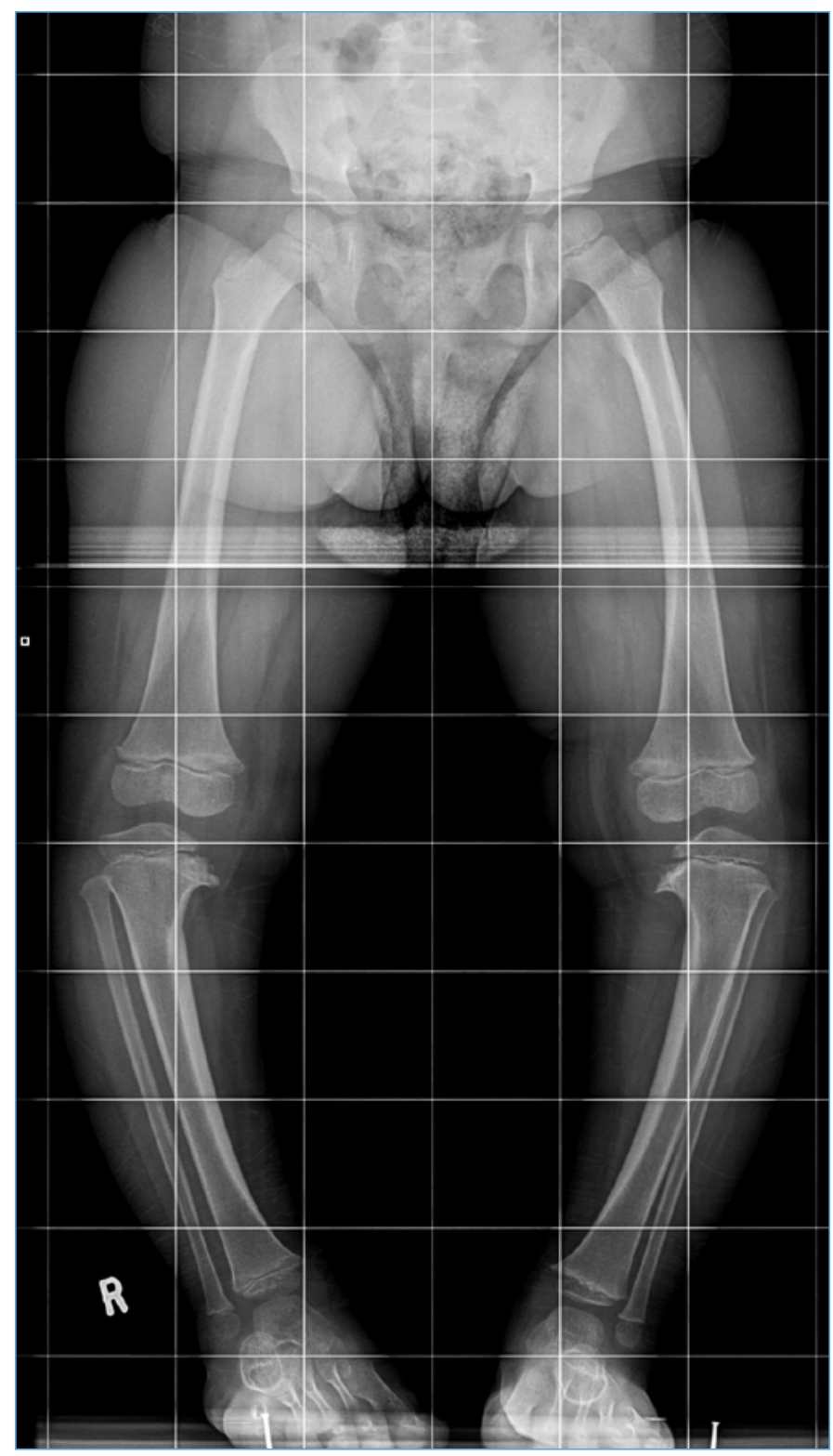

Figure 2. Radiograph of a 3-year-old child with bilateral limb involvement, early-onset Blount's disease

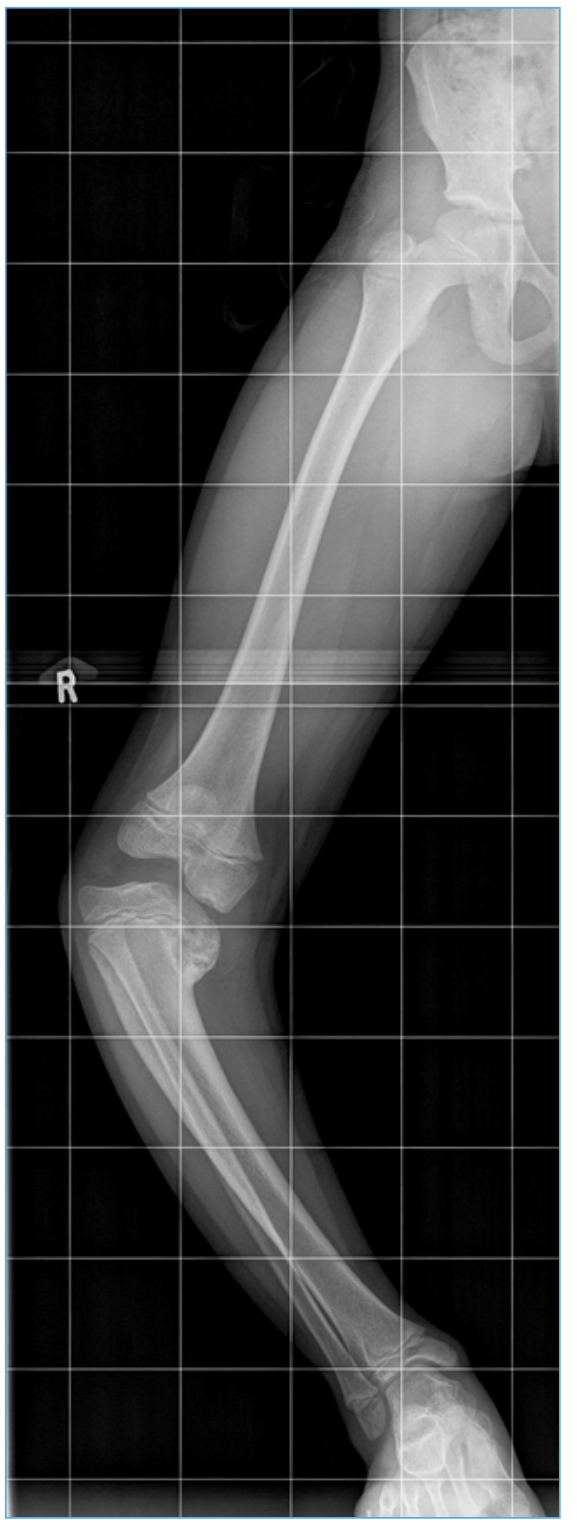

Figure 3. Standing antero-posterior (AP) radiograph of a 9-year-old female patient with Langenskiold stage VI late-onset Blount's disease of the right limb 
A total of 58 knees were studied radiologically (19 bilateral, 20 unilateral disease). Examples of the cases are illustrated in Figures 2 and 3. Using the Pearson correlations, no relationship was found between BMI and TFA ( $r=0.0342, p=0.8364)$. Using $\mathrm{BMI}$ to predict the Langenskiold classification for severity by the univariate logistic regression model, no association was found between $\mathrm{BMI}$ and Langenskiold classification $(p=0.453)$. The mean TFA was $26.88^{\circ}$ (range: $12-50$ ) for early-onset disease and $27.4^{\circ}$ (range: 4-54) for late-onset disease. Using cross-tabulation and Fisher's exact test to assess for an association between onset and Langenskiold classification, eight of nine patients with early-onset Blount's had low-grade (I-IV) Blount's disease (88.9\%) whereas $56.7 \%$ of patients with late-onset Blount's disease had high-grade $(\mathrm{V}-\mathrm{VI})$ Blount's disease. This was statistically significant with $p=0.023$.

\section{Discussion}

The results our cohort show that patients with Blount's disease have a higher BMI compared to the general paediatric population. These results are comparable to studies reported in developed and other developing countries. However, the mean BMI for Blount's disease patients was significantly lower than in the existing literature. ${ }^{13}$

\section{Sex}

In our study population, Blount's disease affected both sexes equally with a comparable number of unilateral and bilateral cases. Similarly, there was an equal presentation of both sexes in early-onset and late-onset Blount's disease groups. A recent meta-analysis by Rivero et al. found that patients with early-onset Blount's disease were more likely to be females than males $(61 \%$ vs $39 \% ; p=0.01) .^{3}$ Inaba et al. in a multi-centre study in Japan found that there were more females in both early-onset and lateonset Blount's disease. ${ }^{26}$ On the contrary, Montgomery et al. found that Blount's disease had a statistically significant positive association with patient's sex, with males 8.16 times more likely to have Blount's disease compared with females. ${ }^{10}$ Sabharwal et al. in their study of 51 Blount's disease patients also found more males affected than females (32 males vs 19 females). ${ }^{27}$ Our study found that male patients had a higher mean BMI value than their female counterparts. Sabharwal et al. also found a higher BMI in males than females (38.2 vs $32.1 p=0.07$ ) in his study of 45 patients with Blount's disease. ${ }^{13}$ On the contrary, Pirpiris et al. found no statistical difference in BMI between males and females, with females having slightly higher BMI values than males $\left(24.6 \mathrm{~kg} / \mathrm{m}^{2}\right.$ in males vs $26.1 \mathrm{~kg} / \mathrm{m}^{2}$ in females, $\left.\mathrm{p}=0.10\right) .{ }^{11}$

\section{Laterality}

Our study found that patients with bilateral disease had significantly higher BMls compared to patients with unilateral disease. Sabharwal et al. also found that patients with unilateral Blount's disease have a lower mean BMI than patients with bilateral Blount's disease (34.7 kg/m $\mathrm{m}^{2}$ and $36.8 \mathrm{~kg} / \mathrm{m}^{2}$ respectively, $\left.\mathrm{p}=0.53\right) .{ }^{13}$ There was no relationship between the onset of Blount's disease and laterality, with equal numbers of unilateral and bilateral cases found in each group. This contrasts with the meta-analysis by Rivero et al. which found more bilateral cases in early-onset Blount's disease patients and a high incidence of unilateral cases in late-onset (adolescent) Blount's disease patients. ${ }^{3}$ Our limited number of early-onset Blount's disease rendered comparison inconclusive.

\section{Body mass index}

The mean BMI values of our study population are significantly lower than those reported in the literature. A retrospective study of 45 Blount's disease patients by Sabharwal et al. found a mean BMI of $35.6 \mathrm{~kg} / \mathrm{m}^{2}$ with mean BMl of $29.2 \mathrm{~kg} / \mathrm{m}^{2}$ for early-onset Blount's disease and $39.7 \mathrm{~kg} / \mathrm{m}^{2}$ for late-onset Blount's disease. ${ }^{13}$ In our study, the mean BMI was $26.5 \mathrm{~kg} / \mathrm{m}^{2}$ with a mean BMI of $24.2 \mathrm{~kg} / \mathrm{m}^{2}$ for early-onset and $27.2 \mathrm{~kg} / \mathrm{m}^{2}$ for late-onset Blount's disease. Malnutrition and environmental effects may have contributed to the difference. ${ }^{15,21-23}$

\section{Race}

Our study population with Blount's disease consisted only of the black race. Although a conclusion cannot be reached, there seems to be a high predisposition of Blount's disease in black children. Rivero et al. found a greater prevalence of Blount's disease among black children, although this predisposition was stronger in lateonset Blount's disease. ${ }^{3}$ A recent study by Lisenda et al. from South Africa also found all the patients in their study to be of black race. ${ }^{15}$ This forms a strong basis to suggest the relationship between black race and Blount's disease.

\section{Onset}

Our study had only nine (23\%) early-onset Blount's patients compared to 30 (77\%) late-onset Blount's disease patients. Although late-onset Blount's patients had a higher mean BMI compared to early-onset Blount's disease, this was not found to be statistically significant. These results are similar to a study by Sabharwal et al. which found that early-onset Blount's disease patients have lower BMI values than late-onset Blount's disease patients. $^{13}$

\section{Severity}

Our study found no statistical difference in severity of angular deformity using TFA in both the early-onset and late-onset diseases and no association with BMI. Dietz et al. have investigated the relationship between obesity and angular deformities in 15 children diagnosed with Blount's disease and found a strong relationship between body weight, TFA and varus deformities. ${ }^{13}$ In a study by Sabharwal et al., a linear correlation was found between obesity and radiographic changes in children with early-onset Blount's disease $(r=0.74, p<0.0001)$ and children with BMl values greater than $40 \mathrm{~kg} / \mathrm{m}^{2}$ who have late-onset Blount's disease. No relationship was found in late-onset Blount's disease patients with $\mathrm{BMI}<40 \mathrm{~kg} / \mathrm{m}^{2}{ }^{13}$

\section{Langenskiold classification}

Our study found that patients with early-onset disease had lowgrade Blount's disease (i.e. Langenskiold I-IV) and more than $50 \%$ of patients with late-onset Blount's disease had high-grade disease (i.e. Langenskiold $\mathrm{V}-\mathrm{VI}$ ). This finding was expected as Langenskiold staging is associated with patient age. ${ }^{2,4-5}$ There was no relationship found between BMI and the Langenskiold classification system. To our knowledge, no study was done to assess the effect of BMI on the Langenskiold classification, but several studies were conducted to assess the relationship between BMI and severity of angular deformity using TFA angles.

The study limitations include the retrospective nature of the study and the limited number of patients due to the low incidence of this condition. The study had a small group of patients with early-onset Blount's disease, thus conclusions between the two groups could 
not be reached. Although increased BMI has a strong association with Blount's disease and probably influences the severity of angular deformities, other factors that may contribute to these changes were not assessed, i.e. vitamin $\mathrm{D}$ deficiencies and early walking age although vitamin $D$ deficiency was not found to be associated with Blount's disease in a recent study. ${ }^{15}$

\section{Conclusion}

Our study demonstrates that our cohort with Blount's disease has a higher BMI than the control population at our institution. Contrary to existing literature, no relationship was found between sex, onset or laterality and Blount's disease in our study. There was also no significant difference in BMls between early-onset and late-onset Blount's disease patients or the severity of the deformities. Although our study only had black patients, a larger multi-centre study is required in the South African population to assess the relationship between race and Blount's disease and to assess the genetic aetiology that may be responsible for the black racial predilection. Our findings support the association between BMI and Blount's disease in children. Measures aimed at decreasing weight and thus childhood obesity may have some effect on the number of children with this condition.

\section{Ethics statement}

The study was conducted after written approval from the Academic Hospital management. Approval from the University MMed committee was obtained. The Faculty of Health Science's Ethics committee approval was obtained (Protocol number: 5/2017) prior to the commencement of the study. All patients' records were assigned a study number and no patient details were divulged in order to protect their confidentiality.

\section{Declaration}

The authors declare authorship of this article and that they have followed sound scientific research practice. This research is original and does not transgress plagiarism policies.

\section{Acknowledgements}

We wish to thank the staff at Paediatric Orthopaedic unit, for their continuous dedication and management of these patients with Blount's disease.

\section{Author contributions}

Kgoedi MN - main author, study conceptualisation, protocol preparation, collection and interpretation of data and preparation of the manuscript

Rischbieter $\mathrm{P}$ - contributed to study conceptualisation, preparation of the protocol and collection of data

Goller R - study supervisor from study conceptualisation, review of protocol, preparation and revisions of the manuscript

\section{ORCID}

Kgoedi MN (D) http://orcid.org/0000-0002-5749-9960

\section{References}

1. Sabharwal S. Blount's disease. J Bone Joint Surg Am. 2009 Jul;91(7):1758-76.

2. Birch JG. Blount's disease. J Am Acad Orthop Surg. 2013 Jul;21(7):408-18.

3. Rivero SM, Zhao C, Sabharwal S. Are patient demographics different for earlyand late-onset Blount's disease? results based on meta-analysis. Journal of Pediatric Orthopaedics B. 2015 November;24(6):515-20.

4. Langenskiold A. Tibia vara. A critical review. Clin Orthop Relat Res. 1989 Sep;246:195-207.

5. Catonne Y, Pacault C, Azaloux H, Tire J, Ridarch A, Blanchard P. Radiological appearances in Blount's disease. J Radiol. 1980 Mar;61(3):171-76.
6. Laville JM, Chau E, Willemen L, Kohler R, Garin C. Blount's disease: Classification and treatment. J Pediatr Orthop B. 1999 Jan;8(1):19-25.

7. Khanfour AA. Does langenskiold staging have a good prognostic value in late onset tibia vara? J Orthop Surg Res. 2012 Jun 7:23.

8. Bathfield CA, Beighton PH. Blount's disease. A review of etiological factors in 110 patients. Clin Orthop Relat Res. 1978 Sep;135:29-33.

9. Gettys FK, Jackson JB, Frick SL. Obesity in pediatric orthopaedics. Orthop Clin North Am. 2011 Jan;42(1):95,105, vii.

10. Montgomery $\mathrm{CO}$, Young $\mathrm{KL}$, Austen $\mathrm{M}$, Jo $\mathrm{CH}$, Blasier RD, Ilyas M. Increased risk of Blount's disease in obese children and adolescents with vitamin D deficiency. J Pediatr Orthop. 2010 Dec;30(8):879-82.

11. Pirpiris M, Jackson KR, Farng E, Bowen RE, Otsuka NY. Body mass index and Blount's disease. J Pediatr Orthop. 2006 Sep-Oct;26(5):659-63.

12. Chan G, Chen CT. Musculoskeletal effects of obesity. Curr Opin Pediatr. 2009 Feb;21(1):65-70.

13. Sabharwal S, Zhao C, McClemens E. Correlation of body mass index and radiographic deformities in children with Blount's disease. J Bone Joint Surg Am. 2007 Jun;89(6):1275-83.

14. Scott $\mathrm{AC}$, Kelly $\mathrm{CH}$, Sullivan E. Body mass index as a prognostic factor in development of infantile Blount's disease. J Pediatr Orthop. 2007 Dec;27(8):921-25.

15. Lisenda L, Simmons D, Firth GB, Ramguthy $Y$, Kebashni T, Robertson AJ. Vitamin D status in Blount's disease. J Pediatr Orthop. 2016 Jul-Aug;36(5):e59-62.

16. Guven A, Hancili S, Kuru LI. Obesity and increasing rate of infantile Blount's disease. Clin Pediatr (Phila). 2014 Jun;53(6):539-43.

17. Ogden CL, Carroll MD, Kit BK, Flegal KM. Prevalence of childhood and adult obesity in the United States, 2011-2012. JAMA. 2014 Feb 26;311(8):806-14.

18. Kosti RI, Panagiotakos DB. The epidemic of obesity in children and adolescents in the world. Cent Eur J Public Health. 2006 Dec;14(4):151-59.

19. Nutrition and South Africa's children [homepage on the Internet]. 2003 [cited 24 June 2016]. Available from: www.soulcity.org.za/ projects/soul-buddyz/soul-buddyz.../nutrition-literature-review.

20. 2000 CDC growth charts for the United States: Methods and development [homepage on the Internet]. Hyattsville, Maryland: DHHS Publication No. (PHS) 2002-1696 May 2002 [cited 04 June 2016]. Available from: www.cdc.gov/growthcharts/cdc_charts.htm.

21. Overview: Child and Maternal Health [homepage on the Internet]. South Africa: UNICEF South Africa 2013 [cited 24 June 2016]. Available from: http://www.unicef.org/southafrica/survival_ devlop_343.htm.

22. Labadarios D, Swart R, Maunder EMW, Kruger HS, Gericke GJ, Kuzwayo PMN. Executive summary of the national food consumption survey fortification baseline South Africa, 2005. The South African Journal of Clinical Nutrition. 2008;21(3):245-300.

23. Labadarios D, Steyn NP, Maunder E, Maclntryre U, Gericke G, Swart R, et al. The National Food Consumption Survey (NFCS): South Africa, 1999. Public Health Nutr. 2005 Aug;8(5):533-43.

24. Hermanus A. Rossouw, Catharina C. Grant, Margaretha Viljoen. Overweight and obesity in children and adolescents: The South African problem. J Afr J Sci. 2012;108(5).

25. Wendee Morgan. Blount's disease. [cited 03 August 2017] Available from: https://pdfs.semanticscholar.org/1c0a/553d1876c6 bf6c69735f5b02b7d1dec68635.pdf

26. Inaba Y, Saito T, Takamura K. Multicenter study of Blount's disease in Japan by the Japanese Pediatric Orthopaedic Association. $J$ Orthop Sci. 2014 Jan;19(1):132-40.

27. Sabharwal S, Zhao C, Sakamoto SM, McClemens E. Do children with Blount's disease have lower body mass index after lower limb realignment? J Pediatr Orthop. 2014 Mar;34(2):213-18. 